\title{
Interactive comment on "Rainfall intensity bursts and the erosion of soils: an analysis highlighting the need for high temporal resolution rainfall data for research under current and future climates" by David L. Dunkerley
}

\section{David Dunkerley \\ david.dunkerley@monash.edu}

Received and published: 11 March 2019

I much appreciate the comments provided on the manuscript by Dr Müller-Thomy. I have adopted the suggestion to refer to the papers cited as exemplifying microcanonical cascade models, rather than simply as 'canonical cascade models'. I have also included the paper by Jebari et al. (2012) in place of Haddad and Rahman (2014). I have added the reference to Müller and Haberlandt (2018) and have referred to their findings about the errors in over-estimation of short-term intensities. I hope that these revisions will make the paper clearer and more informative. 
Interactive comment on Earth Surf. Dynam. Discuss., https://doi.org/10.5194/esurf-2018-94, 2019.
ESurfD

Interactive comment 